\title{
Goal Orientation and Motivational Climate in University Student-Athletes
}

\section{Eylem GENCER ${ }^{1}$ Arda ÖZTÜRK ${ }^{2}$}

'Kirsehir Ahi Evran University, School of Physical Education and Sports, Kirsehir, Turkey Email:eylemgencer@gmail.com

'Harran University, School of Physical Education and Sports, Sanliurfa, Turkey

Email: ardaozturk82@hotmail.com

\begin{abstract}
The aim of the study was to investigate the goal orientation and the motivational climate of university student-athletes and to reveal the relationship between the goal orientation and the motivational climate. The sample of the research consists of 212 student-athletes studying at universities. TEOSQ (Duda, 1989a;1992; Duda and Nicholls, 1992) and PMCSQ (Walling et al., 1993) were used as data collection tools. The results indicated that university student-athletes were task orientated and perceived the motivational climate as mastery climate. Besides, performance climate predicted ego orientation and mastery climate predicted task orientation. Moreover, age and career were negatively related to goal orientation and motivational climate. The results of the research contribute to a better understanding of the motivational process in physical education and sports environments by suggesting some implications both to the practitioners (teachers and coaches) who work in the field and to the researchers who are doing theoretical and empirical studies.
\end{abstract}

Keywords: Goal orientation, Motivational climate, University student-athlete

Citation | Eylem GENCER; Arda ÖZTÜRK (2018). Goal Orientation and Motivational Climate in University StudentAthletes. Asian Journal of Education and Training, 4(4): 290-294. History:

Received: 17 July 2018

Revised: 9 August 2018

Accepted: 15 August 2016

Published: 20 August 2018

Licensed: This work is licensed under a Creative Commons Attribution 3.0 License $(\mathrm{cc}) \mathbf{E Y}$

Publisher:Asian Online Journal Publishing Group
Contribution/Acknowledgement: Both authors contributed to the conception and design of the study.

Funding: This study received no specific financial support

Competing Interests: The authors declare that they have no conflict of interests.

Transparency: The authors confirm that the manuscript is an honest, accurate, and transparent account of the study was reported; that no vital features of the study have been omitted; and that any discrepancies from the study as planned have been explained.

Ethical: This study follows all ethical practices during writing.

\section{Contents}

1. Introduction

2. Method

3. Results 


\section{Introduction}

Motivation is considered as a concept that determines both participation in physical activity and sports in physical education and sports environments and the direction and degree of behaviors in physical education and sports environments. It is argued that motivation embodying ambitions, desires, demand, impulse and interests that stimulate and energize an organism for a specific purpose affects every behavior of human (Cüceloğlu, 2008). In addition, it is stated that in order to understand the motivation of an individual in physical education and sports environments, it is required to comprehend the psychological structures that energize, direct and shape achievement behavior (Roberts et al., 2007). From this point of view, it can be said that the concept of motivation has a directing influence both in our behaviors in daily life and in our behaviors in physical education and sports environments. Similarly, Sage (1977) while describing the motivation, points to the direction and intensity of one's effort. While the direction of the effort means approaching or avoiding a situation; the intensity of the effort explains how much effort is spent in a situation. Even though there are a great number of statements and theories in the literature about motivation, motivation in the sports environment has often been tried to be explained with three views including participant-centered view, situation centered view and interactional view. Participantcentered view suggests that motivated behavior is primarily a function of individual characteristics whereas situation centered view suggests that personal attitudes are insufficient in determining motivation, and motivation level is primarily determined by the environment. Interactional view, on the other hand, states that the best way to understand motivation is to consider the interaction of participant-centered and situation centered views. Interactional view, which is a combination of personal characteristics and situations that help develop motivation, has important implications for teachers and coaches (Weinberg and Gould, 1995; Anshel, 1997).

Achievement Goal Theory, which is one of the most important theories explaining motivation in physical education and sports, is regarded as a social cognitive approach that assumes the individual is an intentional, goaloriented organism that operates in a rational manner and that achievement goals direct individual's achievement beliefs and guide his subsequent decisions and behaviors in achievement context (Roberts, 2012). According to this approach, in order to understand the motivation of an individual, it is necessary to consider the function and meaning of the achievement behavior for the individual and the purpose of the action should be understood (Moran, 2013). The approach, which assumes that individuals give meaning to achievement behaviors through the goals they have embraced, indicates that these goals reflect the aims of the effort to achieve. In other words, Achievement Goal Theory refers to goal types (aims or reasons) that guide achievement-related behaviors (Roberts, 2012).

According to this approach, there are two main goal orientations that individuals have adopted in achieving success in sports environments. These two orientations, which are related to the one's judging his/her own ability level and which can differ according to one's understanding of his/her ability, are expressed as "task orientation" and "ego orientation" (Nicholls, 1984). It is stated that individuals who adopt task orientation focus on skill learning, skill development, mastery and hard work (Roberts, 2012) whereas ego-oriented individuals concentrate on their superior ability and aim to overcome their opponents with less effort (Duda, 1993). Task-oriented athletes are more satisfied with their own performances, enjoy the practice and show more interest in the task. On the other hand, ego-oriented athletes feel more satisfied with their performance, they get more pleasure from sports and they show more interest in sports as they perform better. In the studies conducted, it was revealed that every athlete has goals related to task and ego to a certain degree, and the combination of both of these two independent achievement ideas identifies the athlete (Jagacinski and Nicholls, 1984). Therefore, while the athlete has a skill and task orientation to a certain degree; he/she may wish to remain superior at certain degrees.

Motivational climate, which is believed to have an effect on the athletes' motivation and which is assumed to affect the individual's goal orientations includes various features such as competition level, instructional styles, and the influence of important people on team culture (Roberts and Ommundsen, 1996). According to Ames (1992) motivational climate refers to a structure that is shaped by the attitudes and behaviors of the coaches. In another definition, the perceived motivational climate is how athletes evaluate the environment they are in with the influence of external factors such as coach, family, friends etc. (Shaw et al., 2005).

There are two different motivational climates in a sports environment. The first one is the mastery climate that supports training and learning that include skill development while the second one is the performance climate, which makes it easier to focus on the opponent's talents and what he/she is doing and enables athletes to become star and to overcome competition (Roberts and Ommundsen, 1996).

The studies carried out clearly show that motivational climate is a factor in determining the goal orientations of athletes (Duda, 1989b; Roberts and Ommundsen, 1996; Duda and Whitehead, 1998; Arıburun and Aşçı, 2005; Toros and Koruç, 2005). Roberts et al. (1998) asserted that the motivational climate in which athletes are included in and they perceive is an essential factor contributing to their sportive goals and performance related to these goals. Roberts (2001) pointed out that teachers and coaches build either a mastery or a performance-oriented climate in their teams through various guidelines, reinforcements.

In this regard, this study aims to investigate student-athletes' goal orientation and their perception of motivational climate, to reveal the relationship between these two conceptual structures and to clarify motivational processes, a key term for success in physical education and sport.

\section{Method}

\subsection{Participants}

The sample of the study consisted of a total of 212 male student-wrestlers, consisting of 140 national athletes, who continue their university education and whose age average is $21.09(\mathrm{Sd}=3.38)$. The average year of the participants' sports career is $9.26(\mathrm{Sd}=3.58)$

\subsection{Data Collection Tools}

Task and Ego Orientation in Sport Questionnaire: Task and Ego Orientation in Sport Questionnaire developed by Duda (1989a;1992) and Duda and Nicholls (1992) consists of a total of 13 items, 7 of which are about 
task orientation and 6 of which are about ego orientation. The scale is a five-point Likert type scale. In the scale analysis, the internal consistency of the scale was found to be .79 for task orientation and .81 for ego orientation (Duda and Whitehead, 1998). Duda (1992) determined three-week test-retest reliability of the scale to be .68 for the task orientation and .75 for the ego orientation. Adaptation study of the scale into Turkish was performed by Toros $(2001 ; 2004)$. In the study, the internal consistency of scale was found to be .87 for task orientation and .85 for ego orientation, and three-week test-retest reliability was calculated as .65 for task orientation and .72 for ego orientation.

Perceived Motivational Climate in Sport Questionnaire: Perceived Motivational Climate in Sport Questionnaire developed by Walling et al. (1993) consists of 21 items including 9 items for performance climate and 12 items for mastery climate. The scale is a five-point Likert type scale. In the scale analysis, the internal consistency of the scale was found to be .73 (Selfriz et al., 1992) and .84 (Walling et al., 1993) for performance climate and .80 (Selfriz et al., 1992) and .81 (Walling et al., 1993) for mastery climate. The adaptation study of the scale for Turkish athletes was conducted by Toros (2001). In the study, the internal consistency of the scale was determined to be .84 for mastery climate and .90 for performance climate, and three-week test-retest reliability was found as .66 for the mastery climate and .74 for the performance climate.

\subsection{Data Analysis}

Analyses were performed by using SPSS (Version 20.0). Descriptive statistics including means, standard deviations, bivariate correlation, and linear regression were calculated for the study variables.

\section{Results}

Table-1. Goal Orientation and Motivational Climate Scores of Student-Wrestlers

\begin{tabular}{l|l|l|l}
\hline & \multicolumn{1}{c}{ N } & \multicolumn{1}{c}{ Mean } & \multicolumn{1}{c}{ Sd } \\
\hline Ego Orientation & 212 & 3.43 & .70 \\
\hline Task Orientation & 212 & 3.78 & .67 \\
\hline Performance Climate & 212 & 3.62 & .51 \\
\hline Mastery Climate & 212 & 4.29 & .63 \\
\hline
\end{tabular}

Table 1 presents the goal orientation and the motivational climate scores of student-athletes. Results show that the ego orientation scores mean is 3.43, the task orientation scores mean is 3.78, the performance climate scores mean is 3.62 , and the mastery climate scores mean is 4.29 of student-athletes.

Table-2. Relationships between Goal Orientation and Motivational Climate

\begin{tabular}{l|l|l|l|l|l}
\hline & & Ego Orientation & Task Orientation & Performance Climate & Mastery Climate \\
\hline \multirow{3}{*}{ Ego Orientation } & $\mathrm{R}$ & 1 & .56 & .44 & .30 \\
& $\mathrm{P}$ & & .00 & .00 & .00 \\
& $\mathrm{~N}$ & 212 & 212 & 212 & 212 \\
\hline \multirow{3}{*}{ Task Orientation } & $\mathrm{R}$ & .56 & 1 & .28 & .46 \\
& $\mathrm{P}$ & .00 & & .00 & .00 \\
& $\mathrm{~N}$ & 212 & 212 & 212 & 212 \\
\hline
\end{tabular}

Relationships between the goal orientation and the motivational climate of student-athletes were analysed by bivariate correlation. As seen in Table 1, the greatest correlations between the goal orientation and the motivational climate is observed between ego orientation-performance climate $(r=0.44, p<0.01)$ and task orientation-mastery climate $(\mathrm{r}=0.46, \mathrm{p}<0.01)$.

\begin{tabular}{l|l|l|l|l|l}
\multicolumn{7}{c}{ Table-3. Regression Analysis on Predicting Ego Orientation } \\
\hline Variable & $\mathbf{B}$ & Standart Error & Beta & $\mathbf{t}$ & $\mathbf{p}$ \\
\hline Constant & 1.24 & .31 & & 3.99 & .00 \\
Performance Climate & .60 & .09 & .44 & 7.10 & .00 \\
\hline $\mathrm{R}=0.44, \mathrm{R}^{2}=0.19, \mathrm{~F}(1,210)=50.02, \mathrm{p}=.00$ &
\end{tabular}

Table 3 presents the regression analysis of performance climate on predicting ego orientation. The result reveals that performance climate is a significant predictor of ego orientation $\left(\mathrm{R}=0.44, \mathrm{R}^{2}=0.19, \mathrm{~F}(1,210)=\right.$ $50.02, \mathrm{p}<0.01)$ and it can be stated $19 \%$ of the total variance related to ego orientation is accounted by the performance climate.

Table-4. Regression Analysis on Predicting Task Orientation

\begin{tabular}{l|l|l|l|l|l}
\hline Variable & B & Standard Error & Beta & t & p \\
\hline Constant & 1.71 & .28 & & 6.03 & .00 \\
Mastery Climate & .48 & .07 & .46 & 7.41 & .00 \\
\hline $\mathrm{R}=0.46, \mathrm{R}^{2}=0.21, \mathrm{~F}(1,210)=54.89, \mathrm{p}=.00$ &
\end{tabular}

Table 4 presents the regression analysis of mastery climate on predicting task orientation. As can be seen in the table, mastery climate is a significant predictor of task orientation $\left(\mathrm{R}=0.46, \mathrm{R}^{2}=0.21, \mathrm{~F}(1,210)=54.89, \mathrm{p}\right.$ $<0.01$ ) and it can be stated $21 \%$ of the total variance related to task orientation is accounted by the mastery climate. 
Table-5. Relationships between Age, Career and Goal Orientation and Motivational Climate

\begin{tabular}{l|l|l|l|l|l}
\multicolumn{5}{|c|}{ Table-5. Relationships between Age, Career and Goal Orientation and Motivational Climate } \\
\hline \multirow{3}{*}{ Age } & & Ego Orientation & Task Orientation & Performance Climate & Mastery Climate \\
& $\mathrm{R}$ & -.16 & -.25 & -.08 & -.22 \\
& $\mathrm{P}$ & .02 & .00 & .23 & .00 \\
& $\mathrm{~N}$ & 212 & 212 & 212 & 212 \\
\hline \multirow{3}{*}{ Career } & $\mathrm{R}$ & -.17 & -.15 & -.07 & -.15 \\
& $\mathrm{P}$ & .01 & .03 & .30 & .03 \\
& $\mathrm{~N}$ & 212 & 212 & 212 & 212 \\
\hline
\end{tabular}

In Table 5, relationships between the age, the career and the goal orientation and the motivational climate were analysed by bivariate correlation. Results put forward that the age is negatively and significantly related to the goal orientation (ego orientation, $\mathrm{r}=-.16, \mathrm{p}<0.05$, task orientation $\mathrm{r}=-.25, \mathrm{p}<0.01$ ). Besides, the results also reveal that the age is negatively and significantly (except performance climate) related to the motivational climate (performance climate, $\mathrm{r}=-.08, \mathrm{p}>0.05$, mastery climate, $\mathrm{r}=-.22, \mathrm{p}<0.01$ ). When assessed in terms of the career, similarly to the age, the career is negatively and significantly related to the goal orientation (ego orientation, $r=-$ $.17, \mathrm{p}<0.05$, task orientation $\mathrm{r}=-.15, \mathrm{p}<0.05$ ) and motivational climate (except performance climate) (performance climate, $\mathrm{r}=-.07, \mathrm{p}>0.05$, mastery climate, $\mathrm{r}=-.15, \mathrm{p}<0.05)$.

\section{Discussion and Conclusion}

In this study, it was aimed to investigate the goal orientation of the student-athletes studying at universities and their perception of the motivational climate and to reveal the relationship between these two concepts and also to determine the relationship between age and career variable and the perceptions of goal orientation and motivational climate of the student-athletes.

The findings obtained in the study suggest that the student-athletes were task orientated and perceived the motivational climate as mastery climate. In line with this finding, it can be said that the student-athletes included in the sample concentrated on skill development, skill learning, mastering in the task and hard work, rather than focusing on their own superior skills and defeating their opponents with less effort in goal setting process.

In addition, in the study, the findings related to the relationship between goal orientation of the studentathletes and their perception of motivational climate demonstrated that the greatest correlations between the goal orientation and the motivational climate are observed between ego orientation-performance climate and task orientation-mastery climate. As a result of the correlational results gathered in the study, it was revealed that performance climate is a meaningful predictor of ego orientation, and mastery climate is a meaningful predictor of task orientation. The findings obtained in the study show parallelism with the results of the studies in the literature. Ames (1992) stated that the motivational climate is a structure that is shaped by the attitudes and behaviors of coaches. Likewise, Roberts and Ommundsen (1996) stated that motivational climate includes the influence of important people on team cultures, while Shaw et al. (2005) stated that external factors such as coaches are also influential on the motivational climate. Arıburun and Aşçı (2005) stated that the motivational climate is related to how the training environment is perceived in physical education and sports. Based on these findings, it can be said that individuals such as teachers and coaches having an influence on student-athletes may have a directing role in goal setting process with the motivational climate they create. In this way, by creating a mastery climate in the processes of skill learning and skill development, the concepts of effort and diligence are highlighted in the goal setting process of student-athletes and so it can be ensured that process-oriented goals can be set. Besides, for student-athletes with special abilities, a performance climate can be created so that individuals can be helped to focus on their own superior abilities and contributed to set result-oriented goals based on these abilities. As can be seen in this study and some others, the motivational climate is a concept which affects the goal orientations of student-athletes. In this direction, a unifying model can be created to enable individuals to set both ego-oriented and task-oriented goals. Indeed, an environment that will be created by only focusing on the performance climate may cause student-athletes to concentrate on their superior abilities and determine goals in order to overcome their opponents by means of these abilities, in other words, to determine only the resultsoriented goals and to ignore the concepts of diligence and effort by distracting them from the process. On the other hand, a mastery climate, where effort, diligence and hard work are the primary focus in new skills learning and skill development, which contributes to the emergence of process-oriented goals, can contribute to setting more desired goals by ensuring that the student-athlete focuses not only the result itself but also the process. As is known, the sport is both process-oriented and result-oriented. While process-oriented goals lead individuals to situations such as hard work, skill development, effort, and co-operation, result-oriented goals contribute to individuals to achieve success. Therefore, a combination of mastery and performance climate that is created according to right time and place can contribute to setting both task-oriented and performance-oriented goals in the goal-setting process of student-athletes.

Another finding of the study indicates that there is a negative, meaningful relationship between the age variable and goal orientation of student-athletes. It was seen that as age increases, ego orientation and task orientation decreases. In the light of this finding, it can be seen that the age variable has a negative effect on the goal orientations of student-athletes. In order to make generalizations about this finding, it is certain that conducting new studies is essential. Moreover, in the case that similar results are found in the new researches to be carried out, individuals from lower age groups and upper age groups can be selected and the underlying reason for this situation can be examined in depth by individual interviews. Similar to the age variable, as the year of studentathletes' careers increases, their goal orientation decreases. The reason for this situation may be because the achievements based on a career may make student-athletes satisfied, yet it is clear that new studies are needed to generalize the findings. Finally, it was found out that there is a negative relationship between age and career variable and the student-athletes' perception of motivational climate, and the relationship between age and career variable and the student-athletes' perception of mastery climate is negative and statistically meaningful. This 
finding suggests that age and career variable, as in the goal orientation, may also have a negative effect on motivational climate perceptions of student-athletes.

The results of the study present some implications for both practitioners (teachers, coaches) and researchers. These are as follows: teachers and coaches are the main actors in creating a motivational climate in physical education and sports environments; teachers and coaches can influence the goal orientations of student-athletes with the motivational climate they will create or design. Finally, the motivational environment can be re-arranged by taking into account the decrease in the goal orientation level of student-athletes depending on age and career growth.

Finally, it should be known that there are some limitations to the research. The research is limited to the sample consisting of the student wrestlers studying at universities. New findings on other sports branches may contribute to the validity and generalization of the findings of this research.

\section{References}

Ames, C., 1992. Achievement goals motivational climate and motivational processes. In Roberts, G. C. (Ed.), Motivation in Sport and Exercise. Champaign, Illinois: Human Kinetics. pp: 161-176.

Anshel, M.H., 1997. Sport psychology: From theory to practice. 3rd Edn., Scottsdale, Arizona: Gorsuch Scarisbrick. pp: $115-151$.

Arıburun, B. and H. Aşçı, 2005. A study of goal orientation and motivational climate in American football. Spormeter Physical Education and Sports Science Magazine, 3(3): 111-114. View at Google Scholar

Cüceloğlu, D., 2008. Human and behavior. Istanbul: Remzi Bookstore.

Duda, J.L., 1989a. Relationship between task and ego orientation and the perceived purpose of sport among high school athletes. Journal of Sport and Exercise Psychology, 11(3): 318-335. View at Google Scholar | View at Publisher

Duda, J.L., 1989b. Goal perspectives, participation and persistence in sport. International Journal of Sport Psychology, 20(1): 42-56. View at Google Scholar

Duda, J.L., 1992. Motivation in sport setting: A goal perspective approach. In Roberts, G.C. (Ed.), Motivation in sport and exercise. Champaign, Illinois: Human Kinetics. pp: 57-91.

Duda, J.L., 1993. Goals A social cognitive approach to the study of achievement motivation in sport: In R. N. Singer, M. Murphy, ve L. K. Tennent (Eds.), Handbook on research on sport psychology. NewYoork: Macmillan. pp: 42 1-436.

Duda, J.L. and J.G. Nicholls, 1992. Dimensions of achievement motivation in schoolwork and sport. Journal of Educational Psychology, 84(3): 290-299. View at Google Scholar

Duda, J.L. and J. Whitehead, 1998. Measurement of goal perspectives in the physical domain. In J. Duda (Ed.), Advances in sport and exercise psychology measurement. Morgantown, WV: Fitness Information Technologies. pp: 21-48.

Jagacinski, C.M. and J.G. Nicholls, 1984. Conceptions of ability and related affects in task involvement and ego involvement. Journal of Educational Psychology, 76(5): 909-919. View at Google Scholar | View at Publisher

Moran, A.P., 2013. Sport and exercise psychology: A critical introduction. 2nd Edn., London: Routledge. pp: 43-81.

Nicholls, J.G., 1984. Achievement motivation: Conceptions of ability, subjective experience, task choice, and performance. Psychological Review, 91(3): 328-346. View at Google Scholar | View at Publisher

Roberts, G. and Y. Ommundsen, 1996. Effect of goal orientation on achievement beliefs, cognition and strategies in team sport. Scandinavian Journal of Medicine \& Science in Sports, 6(1): 46-56. View at Google Scholar |View at Publisher

Roberts, G.C., 2001. Understanding the dynamics of motivation in physical activity: The influence of achievement goals on motivational processes. In G. C. Roberts (Ed.), Advances in motivation in exercise and sport. Champaign, IL: Human Kinetics. pp: 1-50.

Roberts, G.C., 2012. Motivation in sport and exercise from an achievement goal theory perspective: After 30 years, where are we? G.C. Roberts, D. Treasure (Eds.), Advances in motivation in sport and exercise. 3rd Edn., Champaign, IL: Human Kinetics. pp: 5-58.

Roberts, G.C., D.C. Treasure and G. Balague, 1998. Achievement goals in sport: The development and validation of the perception of success questionnaire. Journal of Sports Sciences, 16(4): 337-347. View at Google Scholar | View at Publisher

Roberts, G.C., D.C. Treasure and D.E. Conroy, 2007. Understanding the dynamics of motivation in sport and physical activity: An achievement goal interpretation. In G. Tenenbaum \& R. C. Eklund (Eds.), Handbook of sport psychology. Hoboken, NJ, US: John Wiley \& Sons Inc. pp: 3-30.

Sage, G.H., 1977. Introduction to motor behavior. A neuropsychological approach. 2nd. Edn., Reading, MA: Addison-Wesley.

Selfriz, J.J., J.L. Duda and L. Chi, 1992. The relationship of perceived motivational climate to intrinsic motivation and beliefs about success in basketball. Journal of Sport and Exercise Psychology, 14(4): 375-391. View at Google Scholar $\mid$ View at Publisher

Shaw, D.F., P.J. Gorely and R.M. Corban, 2005. Instant notes sport and exercise psychology. New York: Garland Science/BIOS Scientific Publishers. pp: 90-121.

Toros, T., 2001. Effect of goal orientation, motivational climate and features of originality difficulty level to life satisfaction in elite and nonelite male basketball players. Unpublished Master of Science Thesis, Mersin University.

Toros, T., 2004. Rellability and validity of" task and Ego Orienta Tion in sport questionnaire-TEOSQ-" for Turkish athletes. Hacettepe Journal of Sport Sciences, 15(3): 155-166. View at Google Scholar

Toros, T. and Z. Koruç, 2005. The relationship between goal orientation and perceived motivational climate among high school volleyball players in Turkey. Hacettepe Journal of Spor Sciences, 16(3): 135-145. View at Google Scholar

Walling, M.D., J.L. Duda and L. Chi, 1993. The perceived motivational climate in sport questionnaire: Construct and predictive validity. Journal of Sport and Exercise Psychology, 15(2): 172-183. View at Google Scholar |View at Publisher

Weinberg, R.S. and D. Gould, 1995. Foundations of sport and exercise psychology. Champaign JL: Human Kinetics. pp: 59-72, 137-160. 